\title{
Voluntarism To Social Work And Social Services In Bangladesh
}

\author{
Profulla C. Sarker \\ Vice Chancellor \\ Prime University Dhaka, Bangladesh
}

\begin{abstract}
Natural disasters like floods, droughts, cyclones, storms, burning of houses and river bank erosion along with famine and poverty are the frequent causes of damage to crops, lives and property. Every year millions of people directly and indirectly become the victims of these natural calamities. Many of them are displaced by river bank erosion, and migrate to urban areas in search of employment. Many children are involved in child labor; the young girls are victims of trafficking for prostitution, and many of them are victims of violence while working as domestic maid servants. Many of the elderly people become beggars to survive due to the decline of joint family system. Many of the children do not get a chance to go to school. Many of the people have no ability for treatment due to financial constraints. Often the parents are not able to arrange marriage for their young daughters because of high demand of dowry. In many times to solve these problems, voluntary services play vital role in different perspectives. Voluntarism is a process of voluntary action to serve the people in distress situations. The main focus of this paper is to examine to what extent the social work and social services are rooted in voluntarism by individual, community and organizational initiatives in Bangladesh.
\end{abstract}

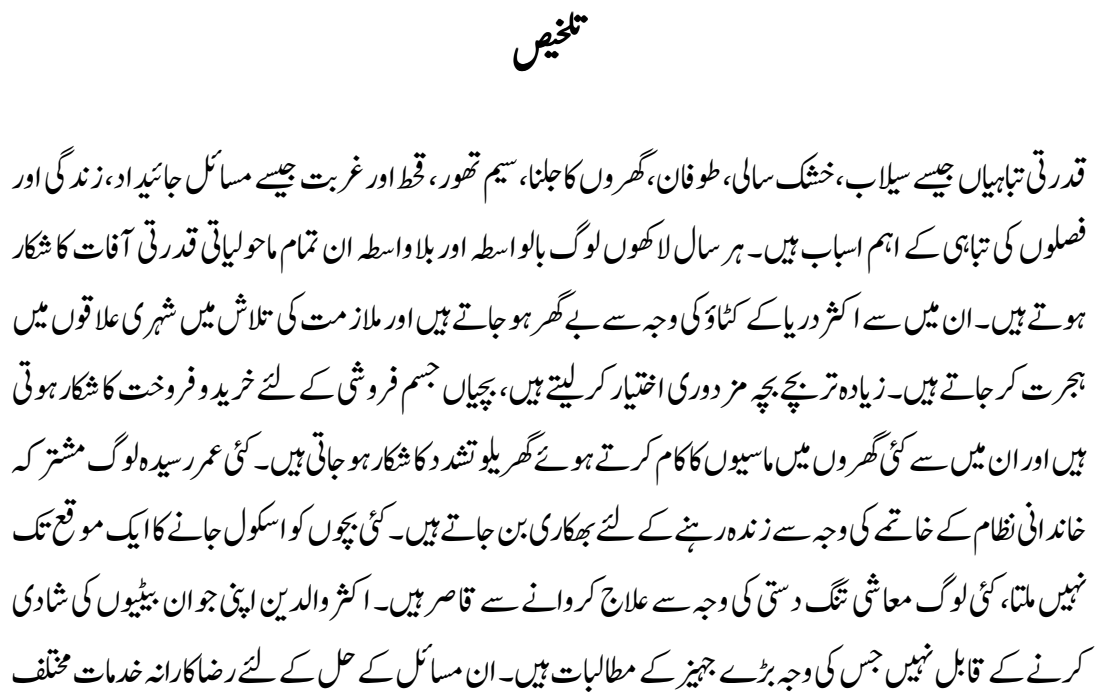




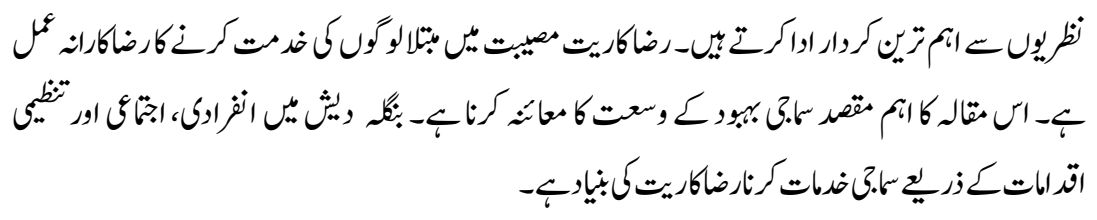

\section{Introduction}

In the process of urbanization, industrialization, landlessness, migration, pauperization and globalization, many social and economic problems have emerged in Bangladesh which are characterized by poverty, unemployment, illiteracy, mal-nutrition, morbidity, infant and maternal mortality, trafficking, prostitution, child labor, drug addiction, terrorism, violence against women, etc. On the other, natural disasters like floods, droughts, cyclones, storms, and river bank erosion are the frequent causes of damages to crops, lives and property along with famine and poverty. Every year millions of people directly and indirectly become the victims of natural calamities. Many of them are displaced by river bank erosion, and migrate to urban areas in search of employment and living in the slums in inhuman conditions. Many children are being involved in child labor, the young girls are victims of trafficking for prostitution and many of them are victims of violence while working as domestic maid servants. Some of the elderly people become the street beggars to survive owing to the decline of joint family system, because of having no alternative.

The main challenge of Bangladesh is to eradicate poverty and to ensure the basic needs and civic facilities of each and every citizen. Poverty reduction is the first priority of each and every government. Unfortunately, poverty remains almost in the same position especially for the weaker section of people. Many of the children grow up on the margins of society, in a state of neglect and deprivation, often without guidance. A significant number of children are being abused by their parents, community people and law enforcing agencies. Many of the children do not get opportunity to go to school. Many of the households do not have hygienic latrine while 95 percent people of Bangladesh have developed the habit of drinking tube-well water being aware of its importance of escaping the attack of water- borne diseases, while unfortunately, arsenic is found in unacceptable concentration in tube-well water in different areas of the country. Chronic arsenic poisoning can manifest a wide range of disease conditions involving various human system, vascular system, respiratory tract etc. (Landrigan,1992).The physical malformation and mental retardation of children 
among the Muslims are higher compared to other religious groups which might be the cause of the practice of cross and parallel cousin marriage and inbreeding. Violence against women in terms of desertion, separation and divorce is a common phenomenon across the world especially in patriarchal society. The government of Bangladesh is not in a position to solve all these problems alone. Each and every government needs cooperation of civil society and voluntary services to solve those problems to improve the quality of life and well being of the people. The main thrust of this is to examine to what extent the social work and social services are rooted in voluntarism through the individual, community and organizational initiatives in Bangladesh.

\section{Conceptual Issues}

The concept of voluntarism is associated with charity and philanthropic impulses which originated from religious injunction and humanitarian sentiments (Titus, 1985; Tesfaye, 1987). It is a part and parcel of the life, society and culture of the people in which they live. The term voluntarism is derived from the Latin word 'voluntas' meaning 'will.' It is defined as the offering of kinds and the services through one's own free will (Barbara \& Khan, 1986). Park (1983) suggested that the heart of voluntarism is the countless individual acts of commitment encompassing an endless variety of tasks. Gove (1986) pointed out that volunteer is one who enters into or offer himself for any service of his own free will. Safrit et al (1994) define voluntarism as operationally giving time, energies, or talents to any individual or group or community for which the volunteer is not paid. The concept of voluntarism is related to a system of voluntary action. More specifically, voluntarism is defined here as the voluntary participation in certain action either individual or group or organizational initiative in order to serve the people in distress situation at the individual, group, and community levels irrespective of religiosity and ethnic identity.

On the other hand, social work grew out of humanitarian and democratic ideals, and its values are based on respect for the equality, worth, and dignity of all people. Since its beginnings over a century ago, social work practice focused on meeting human needs and developing human potential which were instinct from voluntarism. Principles of human rights and social justice are the fundamentals to social work. Social work is an organized process to assist individual, group, and community applying the basic methods and techniques of social case work, social group work, and community organization and community development utilizing 
the local resources with the development of their full capacities and to promote their well being. The social work profession promotes social change, problem solving in human relationships and the empowerment and liberation of people to enhance well being.

Social service is an organized activity to improve the condition of the disadvantaged people in society. It is an organized and joint effort to improve human welfare. In the concept of Friedlander (1961) social service is an organized system which is designed to assist individuals and groups to attain satisfying satisfactory standards of life and health and personal and social relationships which permit them to develop their full capacities and to promote their well-being in harmony with the needs of their family and the community. Social service is defined here as organized efforts designed by the government in order to promote well-being of the people who are in difficult circumstances.

\section{Voluntarism in Bangladesh}

In many cultures 'voluntarism' is obligatory in connection with religious beliefs and values. For example, Tithing in Christianity, Dana in Hinduism and Buddhuism, and Zakat in Islam (Sarker, 2006). Voluntarism consists of a set of values and a set of structures (Wilensky1981 and Bremner, 1988). It is an outcome of deeply ingrained values rather than purely of education, training, or motivation (Hasan, 1993).Voluntarism is rooted at the heart of the philanthropic sector avoiding the materialistic gain. The volunteers and the voluntary organizations are the major vehicles for executing the voluntary services for the well being of the distressed people. There are strong historical roots, culture and heritage about growth and development of the voluntary services in Bangladesh. During the middle ages, a system of Langarkhanas (community feeding center) grew, where the poor were provided with free meals. In times of natural disasters and famines, the Langarkhanas serve as a mode of assisting the affected people. At the same time a system of Dharmagola ( a community store house) was also developed as a preventive measure against crop failure, famine and for helping the needy. The farmers used to contribute a share of their harvest to Dharmagola for use by the community people in times of need (Khan,1978). The charity and voluntary efforts have emerged out since the early nineties of the 20the century with the establishment of educational institutions, charitable dispensaries, orphanages, religious institutions, either through individual effort or community initiative (sarker, 2006). The main sources of voluntarism are the Debottor 
(property is registered in the name of deity or god for the expenditure of worship and welfare activities) which is found among the Hindus. No one can enjoy the ownership rights of this property. It is controlled by the trustee board. The Wakfa (property is donated by the Muslims) for welfare activities under the initiative of a trustee board. Wakfa does not allow individual right of the property. The Zakat is a determined portion taken from wealth and allocated to those deserving it. Every Muslim who possesses a Zakat payable amount for one luner year has to pay 2.5 percent of total wealth for purification of the rest of the total wealth. On the other hand, Sadqah (cash or kind) is to be given in any time to the poor relatives particularly and in general to the poorer section of population. The Fitrah, is practiced by the Muslims and also given to the poor people by the rich which is a sum of money equivalent to the price of 2.75 kilograms of grain for each member of the family. The sahajya (some amount of one time financial support) is given in time of distress situation to the needy persons irrespective of religion and ethnic identity. It might be the cause to meet up dowry demand for the marriage of daughters of poor persons or for the treatment or for the funeral ceremony and so on. More over, viskhya (alms) is given to the beggars by the week end in order to get punya (merit) as well as to get rid of the consequences of ku-karma (misdeed).Many destitute people live on this charity i.e., they live on week end alms.

\section{Voluntarism in Individual Initiative}

Voluntarism in individual initiative means voluntary services provided to the disadvantaged people by the individual initiative. Many philanthropic minded affluent people have established schools, madrashas (institution for religious education for the Muslims) and colleges, for the education of the people in Bangladesh. For example, most of the reputed colleges were established by the zaminders (the land lord) during the British administration .Besides, at the individual initiative, Ranoda Prosad Saha has established a hospital in order to provide health care services to the people. He has also established the Bharateswari Home (a Girls' School) and Kumudiny Girls' College for the Education of the women in a patriarchal society like Bangladesh .The establishment of educational institutions and welfare activities were initiated at the individual level by Rani Bhabani, Nawab Faizunnesa, Raja Promotha Nath and so on. Some of the government officials were also involved in voluntary services. For example, Nurunnabi Choudhury, N.M.Khan, H.S.M.Ishaque, Mahbub Alam Chashi, and Mohiuddin, and Akhter Hamid Khan made sincere 
attempts to promote social services for social development. It should be mentioned that about 40 years ago there was no dormitory for the accommodation of the students at high schools and colleges. Even the number of educational institution was scanty. Under the circumstances, the local people would provide free lodging and food for the students at the individual initiative which is called jaigir. Voluntarism is also rooted in individual initiative by the social reformers like introducing of widow re-marriage by Iswar Chandra Bidya Sagar, abolition of satidaho (sacrifice of wife's life with the cremation of the dead body of husband) by Raja Ram Mohon Roy with the active cooperation of Lord Bentinck, introducing education for the Muslim girls by Begum Rokeya and Nawab Faizunnesa, expansion of education for the Muslims by Haji Mohammad Mohoshin and introducing English education for the Muslims by Sir Syed Ahmed.

\section{Voluntarism in Community Initiative}

Voluntarism in community initiative means the voluntary services given by the initiative of the community people. In ancient and medieval period, voluntarism was associated with education, health care and treatment and promotion of culture (Inamdar,1987) It should be noted that about 80 percent people of Bangladesh live in rural areas. There are more than 68 thousand villages in Bangladesh and each village has one or more than one samaj based on religiosity and ethnic identity. The samaj is a traditional informal institution of the people having jurisdiction over a certain area within a village community (Hasan, 1993). The samaj receives no statutory recognition. Each samaj has an informal council headed by a local leader who is nominated by the people of the respective samaj. The smaj is active for rendering voluntary services for the community people like village defence, maintenance of roads, bridges, culverts, tube well for drinking water, charitable dispensary for treatment and management of schools, mosque, temple, Graveyard, cremation ground, and so on by voluntary labor and financial support raised from the samaj through chanda (subscription). The samaj is also active for organizing cultural and recreational activities through subscription. Some times the religious activities are conducted by the samaj when these take place at the community level.

\section{Voluntarism in Organizational Initiative}

Voluntarism is a part of the cultural heritage of the people of Bangladesh. During the colonial days of 1860, voluntary and charitable organizations in Bengal 
received recognition (Hasan,1993).The first voluntary organization, the Baptist Missionary Society was established in 1794 in Bengal in order to provide medical treatment, education, and spiritual teaching to the rural people (ibid). The emergence of voluntary organizations in Bangladesh is the failure of the government in meeting the basic needs and civic facilities of the people. Each and every voluntary organization has to register with the government under the ordinance of Voluntary Registration Act in Grants and Aid 1961 to get financial support once in a year from the National Council of Social Welfare. Almost all the voluntary organizations are run by volunteers. The missions and visions of the voluntary organizations are to provide services to people who are in distress situation involving them in human resource development activities, which include education, health and sanitation, family planning, skill development training in agriculture, sericulture, pisciculture, social forestry, awareness, legal aid etc. The main objectives of these programs are to make the disadvantaged people self reliant and self sufficient so that they can cope with the undesirable situation to stand on their own feet. Moreover, eye treatment facilities are provided by Lions Club for the poor patients. The Rotary club and the Red Crescent Society also help and cooperation to the distressed people in times of need.

\section{Voluntarism to Social Work and Social Services}

The professional social work and organized social services are originated from the humanitarian out look and religious sentiments and the voluntary activities which were instinct in the mind of the people through philanthropic impulses to provide services for the people who were in distress situation. But the problems are so diversified and acute that the voluntarism could not cope with these situations. To overcome these situations, special knowledge, skills and attitudes are required. These could be gained usefully and profitably through the professional social work and organized social services at the statutory level using the methods and techniques of modern social work. The modern social work in its various forms addresses the multiple, complex transactions between people and their environments. Its mission is to enable all people to develop their full potential, enrich their lives, and prevent dysfunction. The organized social services are provided through different institutions by the trained social workers under the Directorate of Social Services, Ministry of Social Welfare of the Government of Bangladesh. These social services are the baby home for abandoned and unclaimed babies, day care center for the care and protection of the children of working parents, the orphanage for the orphan children which is renamed as 
children family in order to get fictive family support for physical and mental development, services for the street children through Appropriate Resources for Improving Street Children's Environment (ARISE) project, school for blind, school for deaf and dumb, and services for physically handicapped and mentally retarded children through special education.

The Directorate of Social Services has direct programs for the youth to assist them in maximizing their potential and productive capabilities for gainful employment and in the process to improve their living conditions and quality of life (Sarker, 2006). Later on the Ministry of Youth Development was created in 1978 and it was subsequently renamed as the Ministry of Youth and Sports. The major areas of program activities are to create employment opportunities, skill development training for self employment, participatory social services projects for college and university students. Correctional services are provided to the youth offenders and released prisoners in making the necessary social adjustment. The recreational services are also provided for physical, emotional and social development of the youth. The idea of these services for the welfare of the youth is rooted from the youth clubs through which voluntary services were provided for the development of the youth.

Social services are provided for the disadvantaged urban people through Urban Social Services (USS) programs. These are poverty reduction through family development, skill development, income generating activities for weaker section of the people, women empowerment, adult education, sanitation and reproductive health. While, the Rural Social Services (RSS) provide a multi dimensional, comprehensive approach to rural development through skill development training for self employment, poverty reduction, eradication of illiteracy, promotion of birth control devices for small family size, reproductive health and sanitation, and local level leadership training. Moreover, it promotes community civic action programs for development of communication, sanitation, safe water supply for drinking and cooking, construction of community centers, educational institutions, club, social forestry, etc.

In 1998, the government of Bangladesh has introduced a pension program for the poor old people. Under this scheme only 10 oldest poor from each ward get US\$ 5 per month. Half of these beneficiaries are females. The scheme is executed under the Directorate of Social Services. Besides, there are other programs targeting the poor and women, such as vulnerable Group Development (VGD) 
and Vulnerable Group Feeding VGF).Both of these programs aims at, to provide development or food assistance to the poor to improve the quality of life.

\section{Concluding Remarks}

Voluntarism, social work and social services are inter linked and inter connected. Voluntarism, the root of social work and social services provided either formally or informally is an inevitable and important part of everyday life. The informal social service is termed as voluntary social service and on the other hand, the formal social service is termed as statutory social service which is provided by the government. In addition, the formal social services are also provided by the NGOs either individually or in collaborative effort.

The voluntary services are provided on normative and moral perspective instinct by religion, humanitarian sentiments and philanthropic impulses and philosophy of life (Waerness, 1998; Leira, 1993; Thomas, 1993; Sevenhuijsen, 2000). Bearing in mind the importance of the formal and informal social services, the social development is the output of social services which focuses the improvement of standard of living and quality of life of the disadvantaged people. The ultimate goal of voluntarism, social work, and social services is social development which focuses on the well being of the people and quality of life. Every country throughout the world either developed or developing or least developed is facing diversified social problems. In many developing countries, the family and the society are in transition in the age of globalization. In the circumstances, states are not in a position to solve all the problems unless the voluntary organizations do not step forward to take initiative to solve the problems at the community and societal levels through proper utilization of local level resources. Voluntarism instincts the mind of the people to integrate through the attitude of sharing responsibilities, feelings, accountability and social responsibility to individual, to family, to community, to society and lastly to the nation irrespective class, caste, sect, creed, religion and ethnic identity ultimately which contribute to solidarity among the people of community. It also contributes to community stability and well being of the people. 


\section{References}

Barbara, D. Miller and Showkat Hayat Khan (1984). Local Voluntarism and Local Government Finance in Rural Bangladesh: An Overview and Recommendations, The Maxwell School of Citizenship and Public Affairs, New York, Syracuse University.

Bremner, Robert H. (1988). American Philanthropy. Chicago, The University of Chicago Press.

Chowdhury, A.N. (1989).Let Grass Roots Speak: People's Participation Self Help Groups and NGOs in Bangladesh .Dhaka, The University Press Ltd.

Chui, Wing T., Yu C. Wong and Cecilia Chan(1996).Social Work Education for Social Development. Journal of Applied Social Sciences, 21(1):15-25.

David, Brown (1988). Private Voluntary Organizations and Development Partnerships, in Pradip K. Khandanwalla, (ed.), Social Development: A New Role for the Organizational Sciences. New Delhi, Sage Publications.

Friedlander, Walter A. (1961).Introduction to Social Welfare. New Jersey: Prentice-Hall, INC.

Gove, P.B. (1996). Webster's Third International Dictionary of the English Language Unabridged. Springfield, M.A.:Merriam-Webster Inc., Publishers.

Hasan, Samiul (1993). Voluntarism and Rural Development in Bangladesh. Asian Journal of Public Administration, 15(1):82-101.

Inamdar, N.R.(1987). Role of Voluntarism in Development. Indian Journal of Public Administration, 33:420-432.

Khan, Nurul Islam (1978). Social Welfare Services in Bangladesh. Dhaka: Department of Social Welfare.

Kramer, Ralph M.(1973).Future of Voluntary Service Organization, Social Work 18(6):59-69. 
Landrigan, Philip J .(1992).Arsenic, in William, N.R.,(ed.), Environmental and Occupational Medicine.Boston, Little Brown \&Company.

Midgley, James (1995).Social Development: The Development Perspective in Social Welfare. London: Sage Publications.

Park, J. M. (1983). Meaning well is not enough: Perspective on Volunteering. South Planfield,NJ: Group Work Today.

Safrit, R. D., King, J. E.,\& Burcsu, K.(1994). A Study on Voluntarism in Ohio Cities and Surrounding Communities, Columbus: Department of Agricutural Education, The Ohio State University.

Sarker, Profulla C. (2006).Promoting Social Care and Social Services in Bangladesh, in Tan and Vasoo, ed. Challenges of Social Care in Asia. Singapore, Marshal Cavendish.

Sarker, Profulla C.(1999). Gender Dichotomization, Use of Contraceptive Devices and Their Impact on Social Development in Bangladesh. Indian Social Science Review 1(1):203-211.

Shelly, Mizanur Rahman(1989).Voluntary Organization Debate: Fight with the Wind. In Bengali Sangbat, Dhaka, June, 25 (4).

Tesfaye, A.G.C.(1987).Social Welfare Programmes and Social Work Education of Ethiopia. Indian Journal of Social Work X1V11(4):363-377.

Titus, P.M.(1985). From Charity to Social Work. Indian Journal of Social Work X1V1(2): 157-166.

Prof. Dr. Profulla C. Sarker is Vice Chancellor in the Prime University, Dhaka, Bangladesh. 